\title{
RETINAL DETACHMENT IN AIDS-RELATED CYTOMEGALOVIRUS RETINITIS
}

\author{
C. J. SANDY ${ }^{1}$, P. A. BLOOM ${ }^{1}$, E. M. GRAHAM ${ }^{2}$, J. D. FERRIS ${ }^{1}$, S. M. SHAH ${ }^{1}$, \\ W. E. SCHULENBURG ${ }^{1}$ and C. S. MIGDAL ${ }^{1}$ \\ London
}

\begin{abstract}
SUMMARY
Patients with acquired immune deficiency syndrome (AIDS) and cytomegalovirus retinitis (CMVR) are surviving longer due to the use of virostatic medicines and improved treatment of opportunistic infections. As a result, retinal detachment is likely to become an increasingly common cause of visual morbidity in these patients. The incidence and outcome of retinal detachment complicating CMVR was studied at two London AIDS centres. Patients with CMVR were identified prospectively and underwent standard treatment. Retinal detachments were diagnosed during regular follow-up. if retinal reattachment surgery was performed, a standard procedure of vitrectomy and silicone oil internal tamponade was employed. Of 147 patients with CMVR, 41 (28\%) developed retinal detachments (47 eyes). Forty-three detachments were rhegmatogenous and 4 were exudative. Fifteen eyes of 9 patients with rhegmatogenous detachments underwent retinal reattachment surgery. Of these, visual acuity remained stable or improved in 12 eyes $(80 \%)$ in the immediate post-operative period. At the last clinic visit, 8 eyes $(53 \%)$ maintained a visual acuity of $6 / 60$ or better. The visual results of surgery are good in selected patients, bearing in mind the progressive nature of the underlying disease and poor life expectancy.
\end{abstract}

Patients with acquired immune deficiency syndrome (AIDS)-related cytomegalovirus (CMV) retinitis are now surviving longer than when the condition was first described by Holland et al. at the beginning of the AIDS epidemic in $1982 .{ }^{1}$ However, the increased survival has brought with it an increase in retinal detachment as a complication of the disease, which poses a serious threat to vision and thereby quality of life.

Previous reports of the surgical management of

From: ${ }^{1}$ Western Eye Hospital, London; ${ }^{2}$ Medical Eye Unit, St Thomas' Hospital, London, UK.

Correspondence to: Mr C. J. Sandy, Western Eye Hospital, Marylebone Road, London NW1 5YE, UK. retinal detachment have indicated high anatomical success rates but the reports of visual results have been varied. ${ }^{2,3}$ Previously recommended strategies for the repair of CMV-related retinal detachment have included scleral buckling with or without longacting intraocular gases and argon laser photocoagulation. Whilst success has been reported using the former method for the repair of small peripheral detachments, there is now wide acceptance of Freeman et al.'s proposal to manage the majority of CMV-related retinal detachments with vitrectomy, silicone oil internal tamponade and encirclement. ${ }^{4}$

This paper reports our experience of CMV-related retinal detachments and the results of surgery over a 3 year period. This represents the first large prospective study of this type to be performed in the United Kingdom.

\section{MATERIALS AND METHODS}

Patients with AIDS-related cytomegalovirus retinitis (CMVR) and retinal detachment seen between January 1991 and January 1994 at the Western Eye Hospital and St Thomas' Hospital were assessed prospectively. Data collected at each clinic visit, and entered into a computerised database, included date of AIDS diagnosis, data of diagnosis of CMVR, concurrent opportunistic infections, concurrent medications, visual acuity, anterior segment examination and fundal examination. Findings on fundal examination were drawn on a standard form and fundal photographs were taken at each clinic visit and were used at the next visit to assess disease progression.

All patients with CMVR received standard intravenous induction and maintenance treatment with either ganciclovir or foscarnet. Ganciclovir was the treatment of choice and the use of foscarnet was reserved for those patients who had evidence of myelosuppression or intolerance to ganciclovir. Induction treatment was given for 2 weeks or until

Eye (1995) 9, 277-281 CC 1995 Royal College of Ophthalmologists 
the retinitis was in remission. Patients who had stable retinitis were usually seen at 4 week intervals.

Patients with retinal detachments were identified and were referred for a vitreoretinal opinion if surgery was thought to be a treatment option. When considering patients for surgery, the area of retina affected by CMVR, the degree of retinal atrophy of detached retina, the presence of retinal holes, optic nerve involvement, fellow eye involvement and the general health of the patient were all taken into account. Surgery was performed by one of the authors (W.E.S.) at the Western Eye Hospital; no surgical procedures were performed at St Thomas' Hospital. All surgical procedures were performed under general anaesthesia and consisted of a threeport pars plana vitrectomy, silicone oil internal tamponade and encircling explant. All patients received intracameral ganciclovir $(200 \mu \mathrm{g}$ in $0.1 \mathrm{ml})$ after silicone oil insertion and cryotherapy was applied to retinal holes if they were visualised.

Post-operatively patients received topical corticosteroid and broad spectrum antibiotic for 4 weeks. Patients were reviewed the morning after surgery, 1 week post-operatively and at 2 weekly intervals thereafter. Post-operative anatomical success was defined as a reattached retina with no residual subretinal fluid.

\section{RESULTS}

One hundred and forty-seven consecutive patients with CMVR were seen between January 1991 and January 1994. Retinal detachment was identified in 47 eyes of 41 patients $(28 \%)$. The mean time from diagnosis of CMVR to detachment was 25 weeks (range: $0-157$ weeks). In 4 cases (12\%) retinal detachment was diagnosed at presentation of CMVR (1 case bilaterally), and at the last clinic visit 6 of 41 patients $(15 \%)$ had developed bilateral retinal detachments. The probability of developing a retinal detachment was shown to be greater in eyes

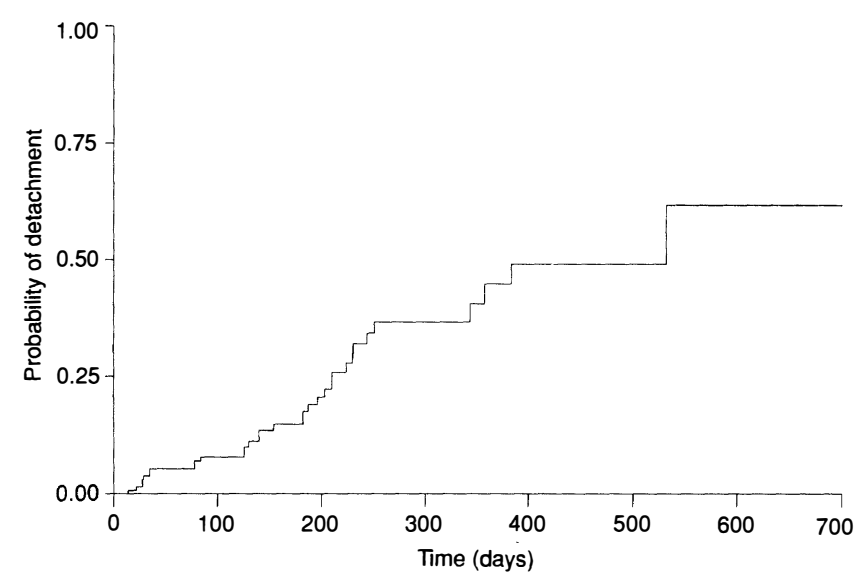

Fig. 1. Kaplan-Meier product-limit survival curve showing the cumulative probability of developing a retinal detachment as a function of the time that an eye had CMVR. that had suffered CMVR for a longer period. Although the overall incidence of CMV-related detachment was $28 \%$ in our cohort of 147 patients with CMVR, the incidence increased to approximately $40 \%$ in those eyes that had been affected with CMVR for 1 year (Fig. 1).

Forty-three retinal detachments were rhegmatogenous and 4 were exudative. Of the rhegmatogenous group, 21 retinas (49\%) detached inferiorly, 5 (12\%) detached superiorly and $7(16 \%)$ were totally detached. CMVR extended into zone 3 of retina in $95 \%$ of patients with rhegmatogenous detachments and only 2 eyes ( $4 \%$ ) had active retinitis at the time of detachment. All 4 exudative detachments were associated with active CMVR and resolved with reinduction treatment.

Fifteen eyes of 9 patients underwent retinal detachment surgery, representing $32 \%$ of all rhegmatogenous retinal detachments seen. Seven eyes were considered inoperable due to direct optic nerve involvement with CMV or sequential optic atrophy, 14 eyes because of extensive CMVR and 7 patients were systemically too unwell to undergo surgery.

Fourteen of 15 procedures (93\%) were considered anatomically successful in the immediate postoperative period and in 13 eyes $(87 \%)$ the retina remained reattached at the last clinic visit. At 4 weeks after surgery the median best corrected visual acuity had increased from $6 / 24$ pre-operatively to $6 /$ 18 and in 12 eyes (75\%) the visual acuity had remained stable or improved (Fig. 2). At the last clinic visit, 8 eyes (53\%) had a visual acuity of $6 / 60$ or better (Fig. 3).

Five eyes $(33 \%)$ suffered a relapse of CMVR between 1 and 6 months post-operatively requiring reinduction treatment. Posterior subcapsular lens opacities developed in 5 eyes (33\%) between 1 and 6 months post-operatively. Only 1 eye underwent extracapsular cataract surgery but the vision did not improve due to CMVR extension to the optic nerve and macula. Optic atrophy developed in 3 eyes $(20 \%)$ between 1 and 6 months post-operatively.

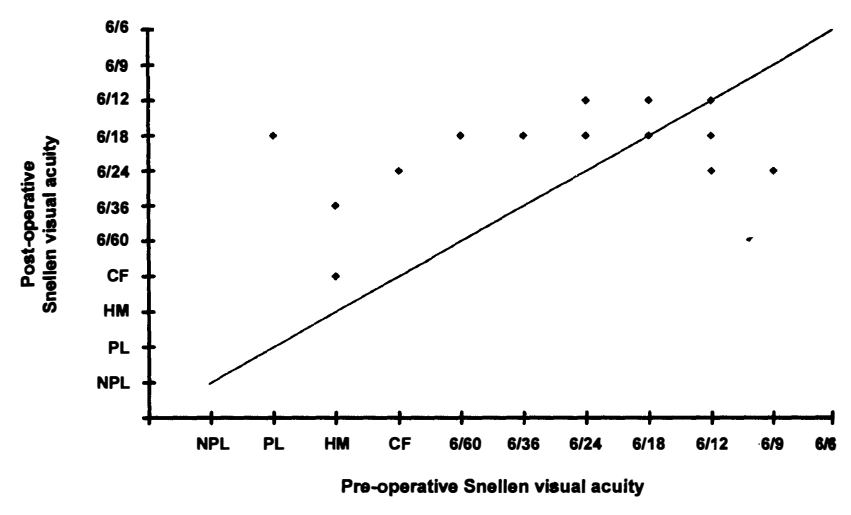

Fig. 2. Visual results of retinal reattachment 4 weeks after surgery. 


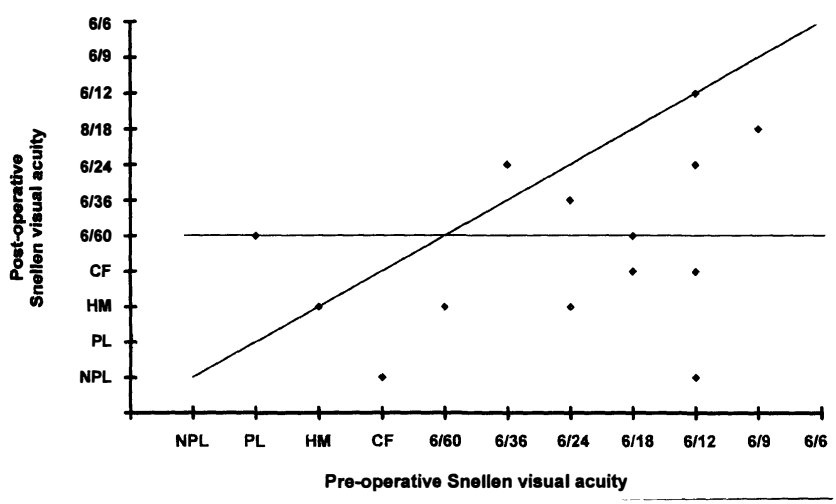

Fig. 3. Visual results of retinal reattachment surgery at the last clinic visit.

One eye suffered a redetachment 4 months postoperatively but the patient did not undergo further surgery due to poor health. One patient has suffered no complications of CMVR or of surgery and 60 weeks after surgery maintains a visual acuity in the affected eye of $6 / 24$. Those patients who have died ( $n$ $=7$ ) had a mean survival after surgery of 37 weeks (range: 3-134 weeks). Two patients are alive at the time of writing (survival times: 60 weeks and 55 weeks).

In 32 patients who did not undergo surgery, visual acuity in the affected eye was $6 / 12$ or better in 5 eyes at presentation and hand movements or worse in 9 eyes. At the last clinic visit, only 2 of these eyes retained vision of $6 / 12$ or better and 11 eyes had an acuity of hand movements or worse. Final visual acuity in the better eye was $6 / 12$ or better in 15 patients $(58 \%)$ and counting fingers or worse in 4 $(15 \%)$. All patients in this group have died, the mean time from retinal detachment to death being 23 weeks (range: 0-113 weeks).

\section{DISCUSSION}

Before the AIDS epidemic, retinal detachments associated with CMVR occurred sporadically in immunosuppressed patients who had undergone organ transplantation., Early in the AIDS epidemic CMVR sufferers only survived a few weeks and retinal detachment was rarely reported as a feature of the disease. ${ }^{1,7-9}$ With increased survival, associated with the improved treatment of opportunistic infections and the use of virostatic medicines, the incidence of retinal detachment in patients with CMVR has increased. It has been proposed that the use of ganciclovir may have been partially responsible for this increase but there is little evidence to support this. ${ }^{4,10}$

The first series of CMV-related detachments was reported by Freeman et al. in 1987 in which $29 \%$ of 17 patients developed retinal detachment. ${ }^{4}$ Subsequent larger series have reported a similar incidence $^{2,3,11-14}$ and in our cohort of 147 patients the incidence was $28 \%$. The probability of developing a CMV-related retinal detachment in our series was dependent on how long an affected eye had CMVR. Our results showed that if an eye had CMVR for a year, the probability of it developing a detachment was approximately $40 \%$ (Fig. 1). This is a similar to the results of Jabs et al. who were the first to analyse the cumulative probability of developing retinal detachments in eyes affected with CMVR. ${ }^{11}$

Although zone 3 of retina was involved in nearly all cases, ${ }^{15}$ CMVR did not show a predilection for any particular quadrant of the fundus and retinal breaks did not tend to develop in a particular retinal site, unlike conventional retinal detachments. This accounts for the fact that approximately half the retinal detachments involved inferior retina. Exudative retinal detachments in CMVR have previously been reported although their aetiology is unclear. ${ }^{14}$ In our study they were always associated with active CMVR and it is possible that they were related to a breakdown of the blood/retinal barrier due to vascular damage. Further study is needed to elucidate the cause of serous detachments in CMVR.

Some initial success has been reported using conventional scleral buckling techniques and argon laser photocoagulation in the repair of CMV-related detachments. ${ }^{2}$ However, the retinal detachments often recurred and the long-term visual results were poor. It has also been shown that argon laser photocoagulation does not prevent the development of retinal detachment in areas of CMVR or in areas of atrophic retina. ${ }^{11,16,17}$ The presence of multiple holes in thin atrophic retina calls for long-term internal tamponade and it is now widely accepted that the majority of cases should be managed with vitrectomy, silicone oil tamponade and encirclement. ${ }^{18}$ In addition to this we use perioperative intracameral ganciclovir in an attempt to slow progression of CMVR. The rationale for this is based on the evidence that intravitreal ganciclovir is effective in treating CMVR. ${ }^{19-23}$ Although to our knowledge no studies have been performed to assess its efficacy in CMV-related retinal detachments, we advocate the routine use of peroperative ganciclovir as it is easy to administer at the time of surgery, has low toxicity and may contribute to increasing the time to progression of retinitis.

The early anatomical and visual results of surgery were encouraging. There was a post-operative improvement in the median visual acuity and visual acuity remained stable or improved in the majority of patients. Due to the progressive nature of CMVR and the complex nature of surgery, it is not surprising that these visual results were not maintained until death. Nonetheless, in over $50 \%$ of patients the final recorded vision in affected eyes was better than $6 / 60$ and the majority of patients with a final visual acuity 
worse than $6 / 60$ had vision of $6 / 36$ or better for several months before suffering a visual deterioration.

The nature of retinitis or the general health of the patient often mitigates against surgery as a treatment option and in our series only $32 \%$ of rhegmatogenous retinal detachments were deemed appropriate for surgical intervention. Our selectivity may be a reason why our visual results were comparatively good. It is important to bear in mind the fact that these visual results are based on Snellen visual acuities and may only provide a limited impression of functional vision. These patients often had extensive areas of retinal destruction with or without optic nerve involvement and their visual fields may have been grossly abnormal. We did not perform visual field testing on these patients but further studies in both uncomplicated CMVR and in CMVrelated retinal detachment woudl provide valuable information regarding functional vision in affected patients.

Post-operatively, the visual acuity in most operated eyes deteriorated to some extent for a variety of reasons. Cataract associated with the use of silicone oil remains a common problem and although it occurred in $33 \%$ of patients, surgery was performed in only 1 patient. No other anterior segment complications of silicone oil were encountered. Optic atrophy developed in $20 \%$ of patients between 1 and 6 months after surgery but it is unclear as to whether this was a complication of surgery or due to underlying disease. This is a much lower incidence than that reported by Dugel et al., who found that optic atrophy developed in $95 \%$ of patients and proposed that a post-operative rise in intraocular pressure may further damage an optic nerve already compromised by poor vascular perfusion. ${ }^{24}$ It has been suggested that the direct effect of silicone oil on the optic nerve may take years to evolve and it is unlikely that it contributed to optic atrophy in our series. ${ }^{25}$ Proliferative vitreoretinopathy has contributed to failure of surgery in some series but this was not our experience. ${ }^{3,4}$ One explanation for this may be that detachments were identified during regular follow-up and surgery was performed usually within 1 week of diagnosis of detachment.

The visual results in our study are encouraging, bearing in mind the progressive nature of CMVR, but stress the need for careful patient selection when considering surgery. It is possible that aggressive treatment of active CMVR, prompt identification of detachments during regular follow-up and a minimal delay before surgery, contribute to anatomical and functional success. Many patients will be unsuitable candidates, but in selected cases surgery helps to maintain visual independence and quality of life throughout the short period of life expectancy.

Key words: Acquired immune deficiency syndrome, Cytomegalovirus retinitis, Retinal detachment, Visual acuity, Vitrectomy.

\section{REFERENCES}

1. Holland GN, Gottleib MS, Yee RD, Schanker HM, Pettit TH. Ocular disorders associated with a new severe acquired cellular immunodeficiency syndrome. Am J Ophthalmol 1982;93:393-402.

2. Orellana J, Teich SA, Leiberman RM, et al. Treatment of retinal detachments in patient with the AIDS. Ophthalmology 1991;98:939-43.

3. Sidikaro Y, Silver L, Holland GN, Kreiger AE. Rhegmatogenous retinal detachments in patients with AIDS and necrotizing retinal infections. Ophthalmology 1991;98:129-35.

4. Freeman WR, Henderly DE, Wan WL, et al. Prevalence, pathophysiology and treatment of rhegmatogenous retinal detachment in treated cytomegalovirus retinitis. Am J Ophthalmol 1987;107:527-36.

5. Broughton WL, Cupples HP, Parver LM. Bilateral retinal detachments following cytomegalovirus retinitis. Arch Ophthalmol 1978;96:618-9.

6. Meredith TA, Aaberg TM, Reeser FH. Rhegmatogenous retinal detachment complicating cytomegalovirus retinitis. Am J Ophthalmol 1979;87:793-6.

7. Friedman AH, Orellana J, Freidman WR, et al. Cytomegalovirus retinitis: a manifestation of the acquired immune deficiency syndrome. Br J Ophthalmol 1983;67:372-80.

8. Palestine AG, Rodrigues MM, Macher AM, Chan C, et al. Ophthalmic involvement in AIDS. Ophthalmology 1984;91:1092-99.

9. D'Amico DJ, Talamo JH, Felsenstein D, et al. Ophthalmoscopic and histologic findings in cytomegalovirus retinitis treated with BW-B759U. Arch Ophthalmol 1986;104:1788-93.

10. Holland GN, Sidikaro Y, Kreiger AE, et al. Treatment of CMV retinopathy with ganciclovir. Ophthalmology 1987;94:815-23.

11. Jabs DA, Enger C, Haller J, de Bustros S. Retinal detachments in patients with cytomegalovirus retinitis. Arch Ophthalmol 1991;109:794-9.

12. Holland GN, Sakamoto MJ, Hardy D, et al. Treatment of cytomegalovirus retinopathy in patient with acquired immune deficiency syndrome: use of the experimental drug 9-[2-hydroxy-1-(hydroxymethyl)ethoxymethyl]guanine. Arch Ophthalmol 1986;104: 1794-800.

13. Jabs DA, Enger C, Bartlett JG. Cytomegalovirus retinitis and acquired immunodeficiency syndrome. Arch Ophthalmol 1989; 107:75-80.

14. Gross JG, Bozzette SA, Mathews WC, Spector SA, Abramson IS, McCutchan JA, Mendez T, Munguia T, Freeman WR. Longitudinal study of CMV retinitis in AIDS. Ophthalmology 1990;97:681-6.

15. Holland GN, Buhles WC, Mastre B, et al. A controlled retrospective study of ganciclovir treatment for cytomegalovirus retinopathy: use of a standardised system for the assessment of disease outcome. Arch Ophthalmol 1989;107:1759-66.

16. Teich SA, Orellana J, Freidman AH. Prevalence, pathophysiology and treatment of rhegmatogenous retinal detachment in treated cytomegalovirus retinitis [letter]. Am J Ophthalmol 1987;104:312-3.

17. Freeman WR, Quicenco JI, Crapotta JA, et al. Surgical repair of rhegmatogenous retinal detachment in 
immunosuppressed patients with cytomegalovirus retinitis. Ophthalmology 1992;99:466-74.

18. Holland GN. The management of retinal detachments in patients with the acquired immune deficiency syndrome [editorial]. Arch Ophthalmol 1991;109:7913.

19. Henry K, Cantrill HL, Fletcher C, et al. Use of intravitreal ganciclovir (dihydroxypropoxymethylguanine) for cytomegalovirus retinitis in a patient with AIDS. Am J Ophthalmol 1987;107:17-23.

20. Ussery FM, Gibson SR, Conklin RH, et al. Intravitreal ganciclovir in the treatment of AIDS associated CMV retinitis. Ophthalmology 1988;95:640-8.

21. Cantrill HL, Henry $\mathrm{K}$, Melroe $\mathrm{H}$, et al. Treatment of cytomegalovirus retinitis with intravitreal ganciclovir: long term results. Ophthalmology 1989;107:367-74.
22. Heinemann MH. Long-term intravitreal ganciclovir for cytomegalovirus retinopathy. Arch Ophthalmol 1989;107:1767-72.

23. Cochereau-Massin I, LeHoang P, Lautier-Frau M, et al. Efficacy and tolerance of intravitreal ganciclovir in cytomegalovirus retinitis in acquired immune deficiency syndrome. Ophthalmology 1991;98:1348-55.

24. Dugel PU, Liggett PE, Lee MB, et al. Repair of retinal detachment caused by cytomegalovirus retinitis in patients with the acquired immune deficiency syndrome. Am J Ophthalmol 1991;112:235-42.

25. Federman JL, Schubert HD. Complications associated with the use of silicone oil in 150 eyes after retinavitreous surgery. Ophthalmology 198;95:870-6. 